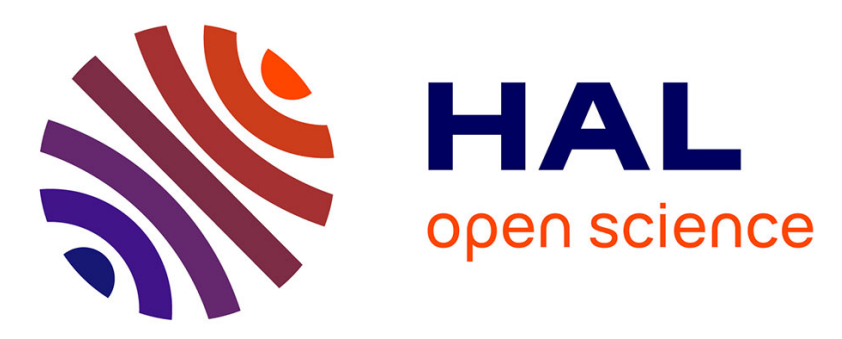

\title{
Hydrogen transport property of polymer-derived cobalt cation-doped amorphous silica
}

Shotaro Tada, Shiori Ando, Toru Asaka, Yusuke Daiko, Sawao Honda, Samuel Bernard, Yuji Iwamoto

\section{- To cite this version:}

Shotaro Tada, Shiori Ando, Toru Asaka, Yusuke Daiko, Sawao Honda, et al.. Hydrogen transport property of polymer-derived cobalt cation-doped amorphous silica. Inorganic Chemistry Frontiers, 2021, 8, pp.90-99. 10.1039/d0qi01035a . hal-03053425

HAL Id: hal-03053425

https://cnrs.hal.science/hal-03053425

Submitted on 18 Dec 2020

HAL is a multi-disciplinary open access archive for the deposit and dissemination of scientific research documents, whether they are published or not. The documents may come from teaching and research institutions in France or abroad, or from public or private research centers.
L'archive ouverte pluridisciplinaire HAL, est destinée au dépôt et à la diffusion de documents scientifiques de niveau recherche, publiés ou non, émanant des établissements d'enseignement et de recherche français ou étrangers, des laboratoires publics ou privés. 


\title{
Hydrogen transport property of polymer-derived cobalt cation-doped amorphous silica
}

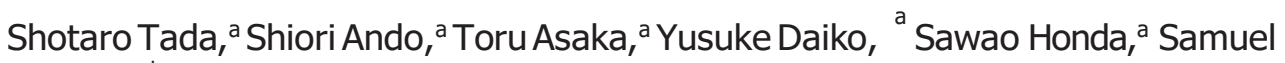 \\ Bernard ${ }^{b}$ and Yuji Iwamoto *a
}

\begin{abstract}
The effect of the local structure of Co-doped amorphous silica on the hydrogen transport property was studied with the aim to improve the high-temperature hydrogen-permselectivity of microporous amorphous silica-based membranes. Co-Doped silica materials with measured $\mathrm{Co} / \mathrm{Si}$ atomic ratios ranging from 0.01 to 0.18 were successfully synthesized through the polymer-derived ceramic (PDC) route. X-ray diffraction (XRD) and high-resolution transmission electron microscopy (HRTEM) analyses confirmed the amorphous state of the polymer-derived Co-doped silica, while both X-ray photoelectron and Fourier transform infrared (FT-IR) spectroscopy analyses revealed that the divalent Co cation $\left(\mathrm{Co}^{2+}\right)$ modified the matrix amorphous silica network to form hydrogen-bonded silanol. After dehydration treatment at 500 ${ }^{\circ} \mathrm{C}$ in argon, hydrogen (H)/deuterium (D) isotope exchange behavior on the surface silanol groups (Si$\mathrm{OH} / \mathrm{OD}$ conversion) of the polymer-derived non-doped and Co-doped amorphous silica was in situ monitored by measuring diffuse reflectance infrared Fourier transform (DRIFT) spectra at $500{ }^{\circ} \mathrm{C}$. The self-diffusion coefficient for $\mathrm{OH} / \mathrm{OD}$ conversion of free silanol groups of non-doped silica was $6.1 \times 10^{-15}$ $\mathrm{m}^{2} \mathrm{~s}^{-1}$, while that on the hydrogen bonded $\mathrm{Si}-\mathrm{OH}$ was found to reach $15.6 \times 10^{-15} \mathrm{~m}^{2} \mathrm{~s}^{-1}$ by Co-doping at the measured $\mathrm{Co} / \mathrm{Si}$ atomic ratio of 0.05 . The effect of the amount of $\mathrm{Co}^{2+}$ doping on the hydrogen transport property was further studied by scanning transmission electron microscopy and electron energy loss spectroscopy (STEM-EELS) analyses, and it was suggested that a rather small amount of Co-doping, i.e. $\mathrm{Co} / \mathrm{Si}$ atomic ratio of 0.05 was effective for enhancing high-temperature hydrogen permeance through microporous amorphous silica-based membranes.
\end{abstract}

\section{Introduction}

Microporous silica membranes with molecular sieve-like properties have relatively high gas permeances, and better thermal stability in comparison with polymer membranes..$^{1-5}$ Thus, they are attractive for application in membrane reactors such as in the steam-reforming reactions of natural gas ${ }^{5-7}$ and in the dehydrogenation of chemical hydrides..$^{-11}$ Recently, amorphous silica-based composite membranes including composite membranes with an oxide system such as zirconium (Zr)-doped silica ( $\mathrm{Si}-\mathrm{Zr}-\mathrm{O}$ ), ${ }^{12}$ nickel (Ni)-doped silica ( $\mathrm{Si}-\mathrm{Ni}-$ O) ${ }^{13}$ and cobalt-doped silica ( $\left.\mathrm{Si}-\mathrm{Co}-\mathrm{O}\right)^{14}$ have been investigated in order to enhance the thermal and hydrothermal stabilities of silica membranes for practical applications.

\footnotetext{
${ }^{a}$ Department of Life Science and Applied Chemistry, Graduate School of Engineering, Nagoya Institute of Technology, Gokiso-cho, Showa-ku, Nagoya 466-8555, Japan. E-mail: iwamoto.yuji@nitech.ac.jp

${ }^{b}$ University of Limoges, CNRS, IRCER, UMR 7315, F-87000 Limoges, France
}

In this category of materials, doping silica with Co was found to be effective for enhancing hydrogen permeance at $500{ }^{\circ} \mathrm{C} .15$ Nanostructural characterization of the Co-doped amorphous silica-based composite membranes revealed that fine particles having a size range of approximately 5 to $20 \mathrm{~nm}$ were formed in situ within an amorphous silica matrix. 15 The selected area electron diffraction ring patterns derived from the nanoparticles were mainly assigned to $\mathrm{CoO}$ and $\mathrm{Co}_{3} \mathrm{O}_{4}$; and metallic Co was found as a minor phase. 15 These results suggested that cobalt oxide in the amorphous silica matrix plays an important role in the enhancement of hydrogen transport.

More recently, amorphous silica-based composite membranes were designed and synthesized through an alternative synthesis approach based on inorganic/organometallic polymers, namely polymer-derived ceramic (PDC) route, and their gas permeation properties were investigated. As an illustration, Co-doped ethoxy polysiloxane-derived silica membranes have been reported to show reversible gas molecular sieving property for high temperature gas separation. ${ }^{16}$ As the polysiloxanes were partly condensed silica precursors, Co-doped silica membranes were prepared by a sol-gel method without any 
extended hydrolysis time and acidic catalyst such as nitric acid or hydrogen peroxide. As a consequence, condensation results in cluster-cluster growth to form very open fractal structures in the polysiloxane sol-gel process. ${ }^{16}$ Thus, the proposed reversible gas molecular sieving property was derived from the alternating volume shrinkage/expansion governed by the reducing/ oxidizing (redox) state change of the Co oxide particles (Co $(\mathrm{OH})_{2}$ and $\left.\mathrm{CoO} / \mathrm{Co}_{3} \mathrm{O}_{4}\right)$ dispersed within the amorphous silica matrix derived from ethoxy polysiloxane. 16 The results also revealed that the oxidation state of Co remained II or III under the reducing conditions which is most probably related to the use of polysiloxanes as polymeric precursors. As reported previously, 14,15 phase separation and subsequent crystallization of Co oxides from the ternary $\mathrm{Si}-\mathrm{Co}-\mathrm{O}$ system easily proceeds during the thermal conversion of precursors prepared through the conventional sol-gel route. This encouraged us to design Co-doped silica membrane materials via the (i) chemical modification of a non-oxidic preceramic polymer as a silica precursor with a Co source, (ii) detailed characterization of the material at each step of the process (Co-modified precursors, pyrolysis intermediates, ...), (iii) investigation of the local structure located at the hetero interface between amorphous silica and Co oxide particles, (iv) study of the relationships between the atomic and/or molecular structure of the ternary amorphous $\mathrm{Si}-\mathrm{Co}-\mathrm{O}$ system and (v) measurement of its hydrogen transport property. Thus, in this study, a series of ternary $\mathrm{Si}-$ $\mathrm{Co}-\mathrm{O}$ amorphous compounds with measured $\mathrm{Co} / \mathrm{Si}$ atomic ratios ranging from 0.01 to 0.18 were successfully synthesized through the PDC route using polysilazanes as non-oxidic precursors of the silica phase and acetylacetonate precursors as the Co source. The Co-modified polysilazane was characterized in detail and then, thermo-chemically converted into Codoped silica. The as-pyrolyzed Co-doped silica samples were chemically and structurally analyzed and hydrogen/deuterium isotope exchange behavior on the surface silanol groups of the amorphous $\mathrm{Si}-\mathrm{Co}-\mathrm{O}$ compounds was in situ monitored. The contribution of the dopant Co to accelerate hydrogen transport through microporous amorphous silica membranes was discussed.

\section{Experimental procedure}

Synthesis of polymer precursors for Co-doped amorphous silica

Commercially available perhydropolysilazane (PHPS, NN110$20,20 \mathrm{wt} \%$ in xylene solution) was provided by AZ Electronic Materials Co., Ltd, Japan. ${ }^{1} \mathrm{H}$ NMR (300 MHz, C6 $\left.\mathrm{D}_{6}, \delta / \mathrm{ppm}\right)$ : 1.6-0.3 (br, NH), 5.8-4.3 (br, SiH); IR (CsI windows $\left./ \mathrm{cm}^{-1}\right)$ : v(N$\mathrm{H})=3374(\mathrm{~m}), \mathrm{v}(\mathrm{Si}-\mathrm{H})=2125(\mathrm{vs}), \delta(\mathrm{N}-\mathrm{H}): 1173(\mathrm{~m}), \delta(\mathrm{N}-\mathrm{Si}-\mathrm{N})$ $=1020-840$ (vs). Cobalt(III)-acetylacetonate $(\mathrm{Co}(\mathrm{acac}) 3$, purity $>98.0 \%$, Tokyo Chemical Industry Co., Ltd, Tokyo, Japan), and super-anhydrous toluene $(99.5 \%$ purity, Wako Pure Chemical Co., Ltd, Osaka, Japan) were used as-received without further purification. The chemical modification of PHPS with Co (acac) 3 was carried out under a dry argon (Ar) atmosphere using Schlenk line and glovebox techniques. The synthesis of Co-modified PHPS samples was performed according to various atomic ratios of $\mathrm{Co}$ in $\mathrm{Co}(\mathrm{acac})_{3}$ to $\mathrm{Si}$ in $\mathrm{PHPS}(\mathrm{Co} / \mathrm{Si})=$ $1 / 8 ; 1 / 20 ; 1 / 40$ and $1 / 80$. The resulting synthesized precursors were labeled as CoPHPS1/8; CoPHPS1/20; CoPHPS1/40 and CoPHPS1/80, respectively. Here, we describe the synthesis of the CoPHPS1/8 sample which is well representative of the synthesis process applied to prepare all polymeric samples. In a typical experiment, a $100 \mathrm{~mL}$ two-neck round-bottom flask equipped with a magnetic stirrer was charged with as-received PHPS (5 mL, $20 \mathrm{wt} \%$ xylene solution) and toluene $(10 \mathrm{~mL})$. Co (acac) 3 (1.099 g, Co/ $\mathrm{Si}=1 / 8)$ was added to the solution at room temperature. The mixture was then stirred at room temperature for $2 \mathrm{~h}$ followed by heating at $10^{\circ} \mathrm{C}$ for additional $12 \mathrm{~h}$ to give the single source precursor of Co-modified PHPS (CoPHPS1/8 sample) as a gelatinous compound.

Conversion to Co-doped amorphous silica

To avoid the vigorous oxidation reaction during the pyrolysis at high temperature, the Co-modified PHPS samples were oxidized at room temperature as follows: after cooling down to room temperature, the reaction mixture was poured into an aluminum tray, and rinsed with acetone, then dried at room temperature. To proceed with further oxidation, the dried residue was exposed to a vapour from aqueous ammonia $\left(\mathrm{NH}_{3}\right)$ at room temperature for $24 \mathrm{~h}$ according to the previously reported procedure. 17,18 The resulting solid precursor was ground to a fine powder using a mortar and pestle, then placed in a quartz boatand heat-treated in an electric muffle furnace (Model FUW220PA, Advantec Toyo Kaisha, Ltd, Chiba Japan) under flowing air by heating from room temperature to $600{ }^{\circ} \mathrm{C}$ in $6 \mathrm{~h}$, maintaining the temperature at $600{ }^{\circ} \mathrm{C}$ for an additional $1 \mathrm{~h}$, and finally furnace cooling down to room temperature to afford Co-doped amorphous silica samples labeled as CoSiO1/8; CoSiO1/20; CoSiO1/40 and $\mathrm{CoSiO} 1 / 80$, respectively.

\section{Characterization}

The attenuated total reflection-infrared (ATR-IR) spectra were recorded on the as-received $\mathrm{Co}(\mathrm{acac})_{3}$, as-received PHPS and chemically modified PHPSs (CoPHPS1/8, CoPHPS1/20, and CoPHPS1/40) with a diamond prism under an incidence angle of $45^{\circ}$ (Model Spectrum 100, PerkinElmer, Waltham, MA, USA).

To study the effect of $\mathrm{Co}^{2+}$-doping on the hydrogen transport property on the amorphous silica surface, hydrogen $(\mathrm{H}) /$ deuterium (D) isotope exchange in the surface silanol groups (Si-OH/OD conversion) of the polymer-derived Co-doped amorphous silica was in situ monitored by measuring IR absorption spectroscopy adopted diffuse reflectance infra-red Fourier transform spectroscopy (DRIFTS) technique (Model Spectrum 100, PerkinElmer, Waltham, MA, USA) according to the following procedure: the Co-doped silica sample was placed within a diffuse reflection cell (Model STJ900C Diffuse IR Heat Cham, S.T. JAPAN Inc., Tokyo, Japan), and subjected to pre-drying to remove adsorbed water at $500{ }^{\circ} \mathrm{C}$ for $20 \mathrm{~h}$ under an argon (Ar) 
flow (4 $\left.\mathrm{mL} \mathrm{min}^{-1}\right)$. The sample was subsequently heat-treated at $500{ }^{\circ} \mathrm{C}$ for an additional $3 \mathrm{~h}$ under a hydrogen flow $(4 \mathrm{ml}$ $\left.\min ^{-1}\right)$, and the initial IR spectrum was recorded. Then, under flowing $10 \%$ deuterium $\left(\mathrm{D}_{2}\right) / \mathrm{Ar}\left(4 \mathrm{~mL} \mathrm{~min}^{-1}\right)$ at $500{ }^{\circ} \mathrm{C}$, the $\mathrm{Si}-$ $\mathrm{OH} / \mathrm{OD}$ conversion was in situ monitored by measuring DRIFT spectra at a specific time interval of 1, 5, 10, 20, 30, 60, 90, 120,150 and $180 \mathrm{~min}$. After the background noise removal, the normalized absorption band intensity in each DRIFT spectrum was calculated by shifting the whole spectrum so as to make the peak intensity at $4000 \mathrm{~cm}^{-1}$ zero. Then, the time dependence on the absorption band intensities of free deuteroxyl (Si-OD) and D-bonded Si-OD in the DRIFT spectra was examined.

Elemental analyses for oxygen, nitrogen and hydrogen (inert-gas fusion method, Model EMGA-930, HORIBA, Ltd, Kyoto, Japan), and carbon (non-dispersive infrared method, Model CS844, LECO Co., St Joseph, MI, USA) were performed for the Co-doped and non-doped silica samples. The Co content in the Co-doped silica samples were analyzed by the energy dispersive X-ray spectrometer (EDS) mounted on a scanning electron microscope (SEM, Model JSM-6010LA, JEOL Ltd, Tokyo, Japan), and evaluated as Co/Si atomic ratio. The chemical compositions of the polymer-derived samples after the heat-treatment in air at $600{ }^{\circ} \mathrm{C}$ are listed in Table 1.

Particle size distribution of the samples after heat-treatment in air at $600{ }^{\circ} \mathrm{C}$ was characterized by the laser diffraction/ scattering method (Model 7995-10 SPA, Nikkiso Co., Ltd, Tokyo, Japan). The average particle size was evaluated as median diameter $\left(D_{50}\right)$ and is listed in Table 2.

$\mathrm{X}$-ray diffraction (XRD) measurement was performed on the $600{ }^{\circ} \mathrm{C}$ heat-treated samples (Model X'pert Pro a 1, Philips Ltd, Amsterdam, The Netherlands).

$\mathrm{X}$-ray photoelectron spectroscopy (XPS) analysis was performed on the heat-treated samples (Model PHI-5000, Ulvacphi, Kanagawa, Japan). The photoelectron binding energy was referenced to the $\mathrm{C}$ 1s peak (at $284.8 \mathrm{eV}$ ) of adventitious carbon. The peak intensity normalization of the XPS spectra

was carried out by dividing all intensity at each spectrum to the peak intensity of oxygen $1 \mathrm{~s}$ in the spectrum.

Transmission electron microscopy (TEM) observations and high-angle annular dark-field-scanning transmission electron microscopy (HAADF-STEM) observations were performed on the heat-treated powder samples (CoSiO1/20 and $\mathrm{CoSiO} 1 / 8)$ in a JEOL JEM-ARM200F operated at an acceleration voltage of $200 \mathrm{kV}$. The size of the electron probe was approximately

Table 1 Chemical composition of polymer-derived samples after heattreatment at $600{ }^{\circ} \mathrm{C}$ in air

\begin{tabular}{lllllll}
\hline & \multicolumn{2}{l}{ Co/Siratio $(-)$} & & \multicolumn{2}{l}{ Content $(w t \%)$} & \\
\cline { 2 - 3 } Sample & Calc. & Obs. & & Carbon & Nitrogen & Oxygen \\
\hline CoSiO1/80 & 0.01 & 0.01 & & 0.15 & 0.07 & 45.46 \\
CoSiO1/40 & 0.03 & 0.03 & & 0.07 & 0.00 & 37.74 \\
CoSiO1/20 & 0.05 & 0.05 & & 0.00 & 0.20 & 41.95 \\
CoSiO1/8 & 0.13 & 0.18 & & 0.07 & 0.24 & 32.37
\end{tabular}

Table $2 D_{50}$ of polymer-derived non-doped and Co-doped silica samples

Sample $\mathrm{SiO}_{2} \mathrm{CoSiO} 1 / 80 \mathrm{CosiO} 1 / 40 \mathrm{CoSiO} 1 / 20 \mathrm{CoSiO} 1 / 8$

\begin{tabular}{llllll}
\hline$D_{50}(\mu \mathrm{m})$ & 20.10 & 21.50 & 20.44 & 23.46 & 23.30
\end{tabular}

$0.1 \mathrm{~nm}$. The convergent angle and the detector collection angle were $22 \mathrm{mrad}$ and 68-280 mrad, respectively. Analytical investigations were carried out by electron energy loss spectroscopy (EELS) using a Gatan Quantum ERS with an incidentelectron beam-energy of $200 \mathrm{keV}$.

\section{Results and discussion}

Synthesis of cobalt cation-doped amorphous silica

Chemical structure of Co-modified PHPS. The typical ATR-IR spectra of Co-modified PHPS samples (CoPHPS1/8, CoPHPS1/ 20 and CoPHPS1/40) were compared with those recorded for PHPS and Co(acac) 3 as shown in Fig. 1. The as-received PHPS exhibited absorption bands at $2152 \mathrm{~cm}^{-1}$ (vSi-H), $1175 \mathrm{~cm}^{-1}$ $(\delta \mathrm{N}-\mathrm{H})$ and $832 \mathrm{~cm}^{-1}$ (ठSi-N-Si). ${ }^{19}$ The as-received Co(acac) 3 presented absorption bands correspond to the ligand acetylacetonate (acac) at $1573 \mathrm{~cm}^{-1}$ (סCVO) and $1518 \mathrm{~cm}^{-1}$ $(\delta \mathrm{C} \vee C) .{ }^{20}$ In addition to the characteristic absorption bands attributed to the Si-H, N-H and Si-N-Si of PHPS, Co-modified PHPS samples exhibited a new absorption band around $930 \mathrm{~cm}^{-1}$ assigned to Si-O-Co(Fig. 1 b). ${ }^{21}$ Moreover, the following changes in the spectra were detected: a new absorption band appeared around $1110 \mathrm{~cm}^{-1}$ assigned to the $\mathrm{C}-\mathrm{N}$ bond, 22 the $\mathrm{C}-\mathrm{N}$ band intensity increased with increasing the $\mathrm{Co} / \mathrm{Si}$ atomic ratio. Oppositely, the $\mathrm{Si}-\mathrm{H}$ band intensity decreased with increasing the $\mathrm{Co} / \mathrm{Si}$ atomic ratio. The CoPHPS1/8 sample presented absorption bands attributed to the $\mathrm{C} \boldsymbol{V O}$ and $\mathrm{CVC}$ of the acac ligand. However, the detected CVO band became
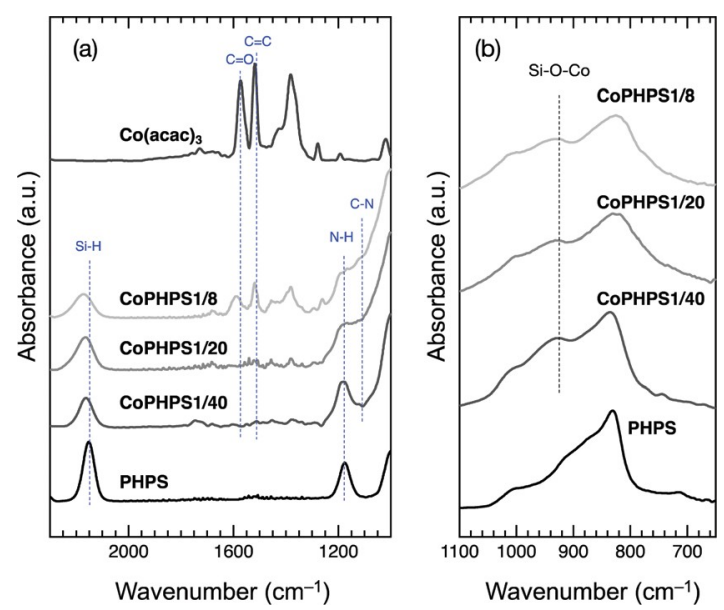

Fig. 1 (a) ATR-IR spectra of the as-received PHPS, Co(acac)3 and typical Co-modified PHPS samples (CoPHPS 1/8, CoPHPS $1 / 20$ and CoPHPS $1 / 40$ samples): 2300 to $1000 \mathrm{~cm}^{-1}$ and (b) 1100 to $650 \mathrm{~cm}^{-1}$. 
broader and shifted toward a higher wavenumber, which suggested that the electron density of a certain number of the CVO double bond increased as a result of $\mathrm{Si}-\mathrm{O}-\mathrm{Co}$ bond formation.

Based on the results obtained by the FTIR spectroscopy analysis, a possible reaction scheme for the present chemical modification of PHPS with $\mathrm{Co}$ (acac) 3 has been suggested as shown in Fig. 2: the nucleophilic conjugate addition of the $\mathrm{N}-$ $\mathrm{H}$ group in PHPS to the acac ligand of $\mathrm{Co}(\mathrm{acac})_{3}$ led to the formation of enamine derivative (1) associated with the elimination of (acac) ${ }_{2} \mathrm{Co}-\mathrm{OH}$ (2). Subsequently, Si-O-Co bond formation proceeded via the dehydrocoupling reaction between the $\mathrm{Si}-\mathrm{H}$ group in PHPS and the (acac) ${ }_{2} \mathrm{Co}-\mathrm{OH}$ formed in situ to give the Co-modified PHPS represented by a series of four precursors labeled as CoPHPS1/8, CoPHPS1/20, CoPHPS1/40 and CoPHPS $1 / 80$.

Conversion to Co-doped amorphous silica. The as-syn- thesized precursors were heat-treated at $600{ }^{\circ} \mathrm{C}$ in flowing air to form the title samples labeled as $\mathrm{CoSiO} 1 / 8, \mathrm{CoSiO} 1 / 20, \mathrm{CoSiO} 1 / 40$ and CoSiO1/80. Table 1 lists the chemical compo- sitions of the polymer-derived samples after the heat-treatment in air at $600^{\circ} \mathrm{C}$. The measured $\mathrm{Co} / \mathrm{Si}$ atomic ratios of the heat- treated samples were well controlled as fixed at the polymer level, except for the CoSiO1/8 sample which was found to be 0.18 , higher than the calculated value $(0.13)$ used for the single source precursor synthesis. One possible reason for the higher $\mathrm{Co} / \mathrm{Si}$ ratio is due the side reaction: ${ }^{23}$ With increasing amount of alcohol derivative to modify PHPS, Si-N bond clea- vage tends to proceed which lowers the polymer-inorganic compound conversion yield due to the volatilization during pyrolysis up to $600^{\circ} \mathrm{C}$ of low molecular weight silazane species formed in situ by the Si-N cleavage. As a result, the Si content in the Co-doped $\mathrm{SiO}_{2}$ decreased, i.e. Co/Si ratio became larger than the nominal one. The residual $\mathrm{C}$ and $\mathrm{N}$ in the pyrolyzed samples were less than 0.2 and $0.3 \mathrm{wt} \%$, respectively. The combination of the FTIR and elemental analysis results revealed that (i) the chemical modification of PHPS occurred via the formation of $\mathrm{Si}-\mathrm{O}-\mathrm{Co}$ bridges in the derived polymers composed of Si, C, N, O, H and Co and (ii) the heat-treatment in air at $600{ }^{\circ} \mathrm{C}$ completed the oxidative cross-linking of the polymer to form ternary ceramics only composed of $\mathrm{Si}, \mathrm{O}$ and
Co elements. Heat-treated samples were found as X-ray amorphous as shown through the XRD patterns of the four investigated ceramic samples (Fig. 3(a)). In order to investigate the
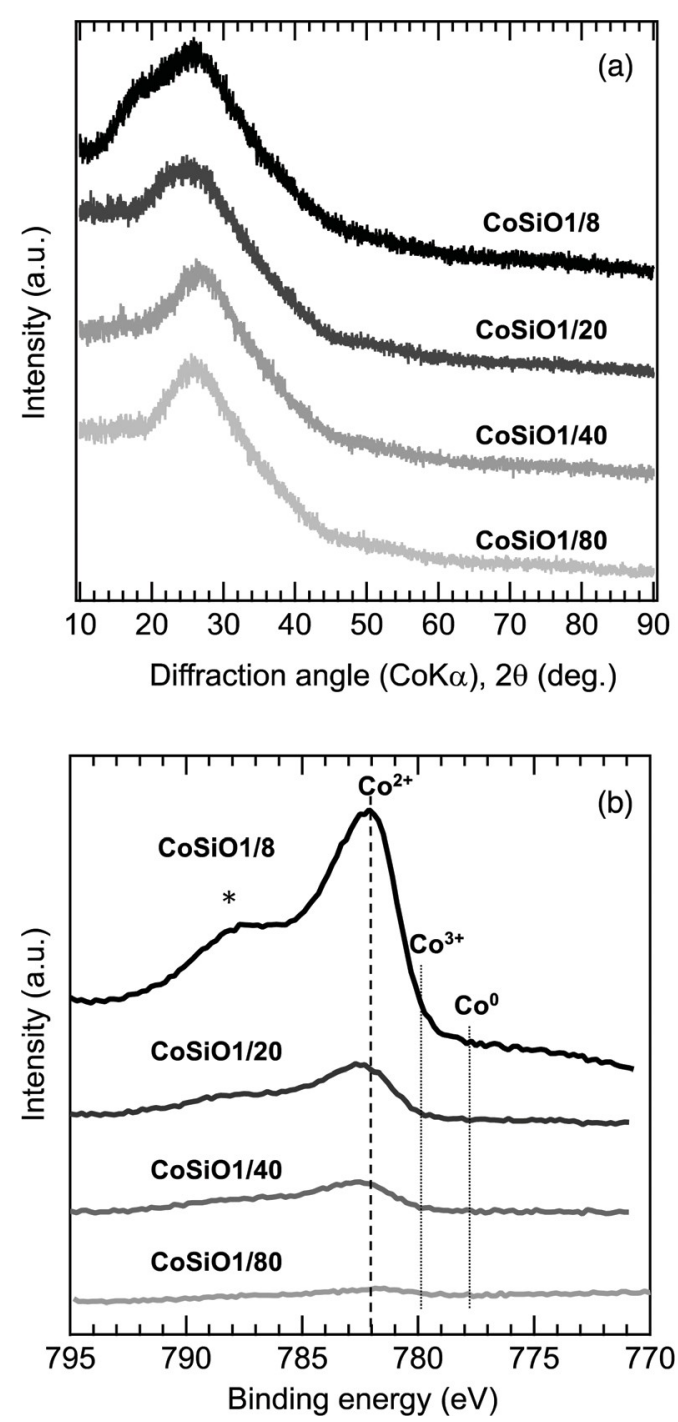

Fig. 3 (a) XRD patterns and (b) XPS spectra of polymer-derived Codoped amorphous silica samples.
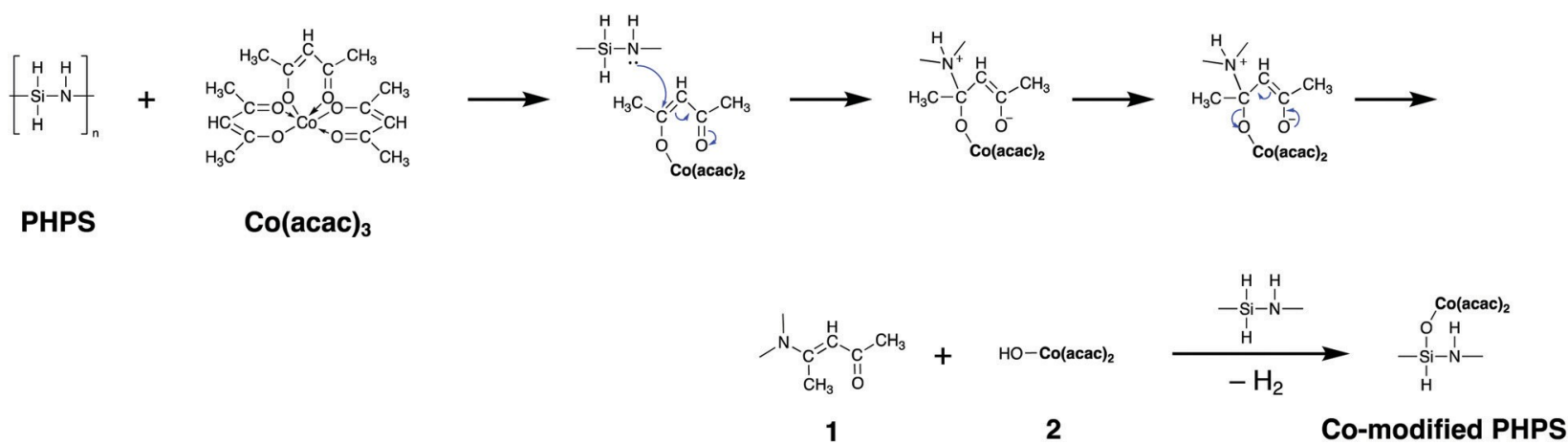

Fig. 2 Possible reaction scheme suggested for the chemical modification of PHPS with Co(acac)3. 
oxidation state of the Co-doped silica samples, XPS has been applied. The results are shown in Fig. 3(b). Consistent with the analytical $\mathrm{Co} / \mathrm{Siatomic}$ ratio from 0.01 ( $\mathrm{CoSiO} 1 / 80 \mathrm{sample}$ ) to 0.05 (CoSiO1/20 sample), a broad peak centered at $782 \mathrm{eV}$ increased in intensity. This peak was assigned to $\mathrm{Co}^{2+} .{ }^{24} \mathrm{At}$ the $\mathrm{Co} / \mathrm{Si}$ atomic ratio of 0.18 (CoSiO1/ 8 sample), another broad peak appeared at around $788 \mathrm{eV}$ corresponding to a $\mathrm{Co}^{2+}$ satellite peak (labeled * in the graph), while those due to $\mathrm{Co}^{3+}$ $(779.9 \mathrm{eV})$ and metallic-Co $(777.8 \mathrm{eV})^{25}$ were not observed. In this study, the Co modification within PHPS was performed at the molecular level via the formation of the $\mathrm{Si}-\mathrm{O}-\mathrm{Co}$ bridge. Thus, Co species were highly dispersed within the Co-doped amorphous silica as shown in XRD patterns (Fig. 3(a)). These results revealed that crystallization of Co species was suppressed to afford $\mathrm{Co}^{2+}-$ modified amorphous $\mathrm{SiO}_{2}$ through the PDC route investigated in this study.

To investigate the bonding state of the sample surface, DRIFT spectra were recorded and are shown in Fig. 4. As shown in Fig. 4(a), the DRIFT spectrum of the as-synthesized amorphous silica presented a very broad absorption band around $3400 \mathrm{~cm}^{-1}$ due to adsorbed water. In order to remove the adsorbed water and to construct the surface conditions of hydrogen transport at high temperature $\left(500{ }^{\circ} \mathrm{C}\right), 15$ an additional heat treatment was performed at $500^{\circ} \mathrm{C}$ for $20 \mathrm{~h}$ under an Ar flow within the DRIFTS chamber. When the adsorbed water was removed, the spectrum presented one dis-

tinct peak at $3732 \mathrm{~cm}^{-1}$ assigned to the $\mathrm{Si}-\mathrm{OH}$ group

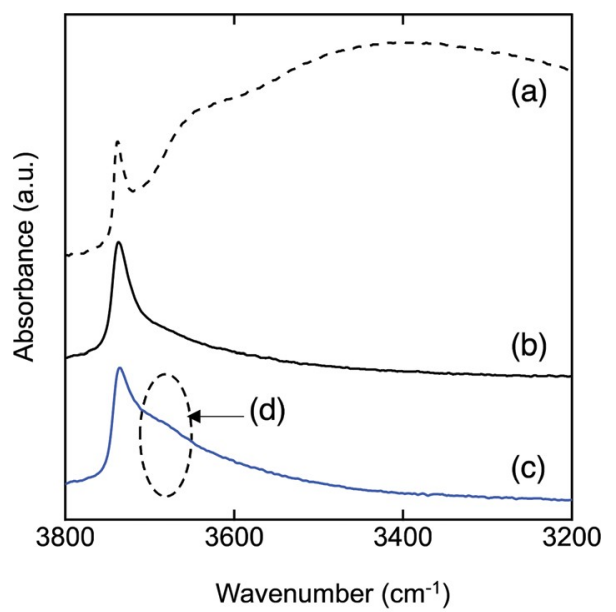

(d)

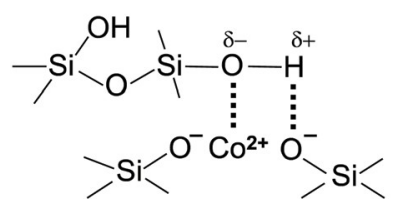

Fig. 4 DRIFT spectra in situ measured for PHPS-derived amorphous silica, (a) as-synthesized, (b) after dehydration treatment at $500{ }^{\circ} \mathrm{C}$ in a vacuum, and (c) Co-doped amorphous silica (CoSiO1/20 sample) after dehydration treatment at $500{ }^{\circ} \mathrm{C}$ in $\mathrm{Ar}$, which suggested (d) the for- mation of hydrogen bond in the $\mathrm{Co}^{2+}$-doped amorphous silica around $3690 \mathrm{~cm}^{-1}$.
(Fig. 4(b)). ${ }^{26,27}$ As a typical result, the DRIFT spectra of the $\mathrm{CoSiO} 1 / 80$ sample after the dehydration treatment at $500{ }^{\circ} \mathrm{C}$ are shown in Fig. 4(c). In addition to the sharp adsorption band assigned to free $\mathrm{Si}-\mathrm{OH}$ at $3733 \mathrm{~cm}^{-1}$, the spectrum exhibited a broad absorption band around $3690 \mathrm{~cm}^{-1}$ attributed to hydrogen (H)-bonded $\mathrm{Si}-\mathrm{OH}$ groups. ${ }^{28,29}$ Such a broad absorption band was observed for all the Co-doped amorphous silica samples (Fig. $\mathrm{S} 1 \dagger$ ). This indicates that the divalent $\mathrm{Co}^{2+}$ cation modifies the amorphous silica network to form $\mathrm{H}$ bonded silanol as shown in Fig. 4(d).

\section{$\mathrm{Si}-\mathrm{OH} / \mathrm{OD}$ conversion behaviors}

To study the hydrogen transport property, OH/OD conversion behaviors were studied for free $\mathrm{Si}-\mathrm{OH}$ and $\mathrm{H}$-bonded $\mathrm{Si}-\mathrm{OH}$, respectively. After the dehydration treatment at $500{ }^{\circ} \mathrm{C}$, DRIFT spectra were recorded for all the samples at $500{ }^{\circ} \mathrm{C}$ under a $10 \%-\mathrm{D}_{2} /$ Ar flow at the specific time interval from 1 to $180 \mathrm{~min}$. Fig. 5(a) shows the DRIFT spectra for the non-doped amorphous silica measured as a reference sample. Consistent with the $\mathrm{D}_{2}$ exposure time, the intensity of the absorption band due to the free $\mathrm{Si}-\mathrm{OH}$ at $3732 \mathrm{~cm}^{-1}$ decreased, while a new band at $2752 \mathrm{~cm}^{-1}$ increased in intensity. After $180 \mathrm{~min}$, the new band became dominant.

Based on the detected wavenumbers of $\mathrm{V}_{\mathrm{OH}}$ and $\mathrm{v}_{\text {new }}$ as $\mathrm{V}_{\mathrm{OD}}$, the isotope shift factor (i) was evaluated:

$$
i \frac{1 / 4}{v_{\text {new }}}{ }^{1 / 4} v_{\mathrm{OD}} \underline{v_{\mathrm{OH}}}
$$

The experimental $i$ value was 1.356 and well consistent with the literature data (1.35-1.36). ${ }^{30}$ Thus, the new band was assigned to deuteroxyl (Si-OD). In addition to the free $\mathrm{Si}-\mathrm{OH}$, the $\mathrm{OH} / \mathrm{OD}$ conversion for $\mathrm{H}$-bonded $\mathrm{Si}-\mathrm{OH}$ was successfully monitored for all the Co-doped samples (Fig. S1†). As a typical result, the DRIFT spectra for the CoSiO1/20 sample are shown in Fig. 5(b). As listed in Table 3, the $i$ values evaluated for the free $\mathrm{Si}-\mathrm{OH}$ and the $\mathrm{H}$-bonded $\mathrm{Si}-\mathrm{OH}$ were in the range of 1.356 to 1.360 , and they were also compatible with the abovementioned literature data. 30

The OH/OD conversion behaviour was further assessed using the self-diffusion coefficient of deuterium evaluated according to the procedure reported by Fishman et al. 31,32 The following equation based on Fick's second law has been derived in order to estimate the diffusion coefficient for the $18 \mathrm{O}$ and $16 \mathrm{O}$ exchange in oxide-ion conductors:

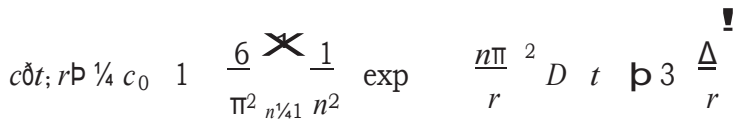

where $D\left[\mathrm{~m}^{2} \mathrm{~s}^{-1}\right]$ is the self-diffusion coefficient; $r[\mathrm{~m}]$ is the particle radius; $c$ [at $\%$ ] is the $18 \mathrm{O}$ concentration; $c 0$ [at $\%$ ] is the

${ }^{18} \mathrm{O}$ concentration of the sample oxide equilibrium to the ${ }^{18} \mathrm{O}$ atmosphere; $\Delta[\mathrm{m}]$ is the monolayer thickness; $t[\mathrm{~s}]$ is the isothermal annealing time.

In general, the surface diffusion coefficient of oxygen is much higher than the volume diffusion coefficient. For instance, in the case of $\mathrm{LaMnO}_{3+\delta}$ perovskite, it was found that 

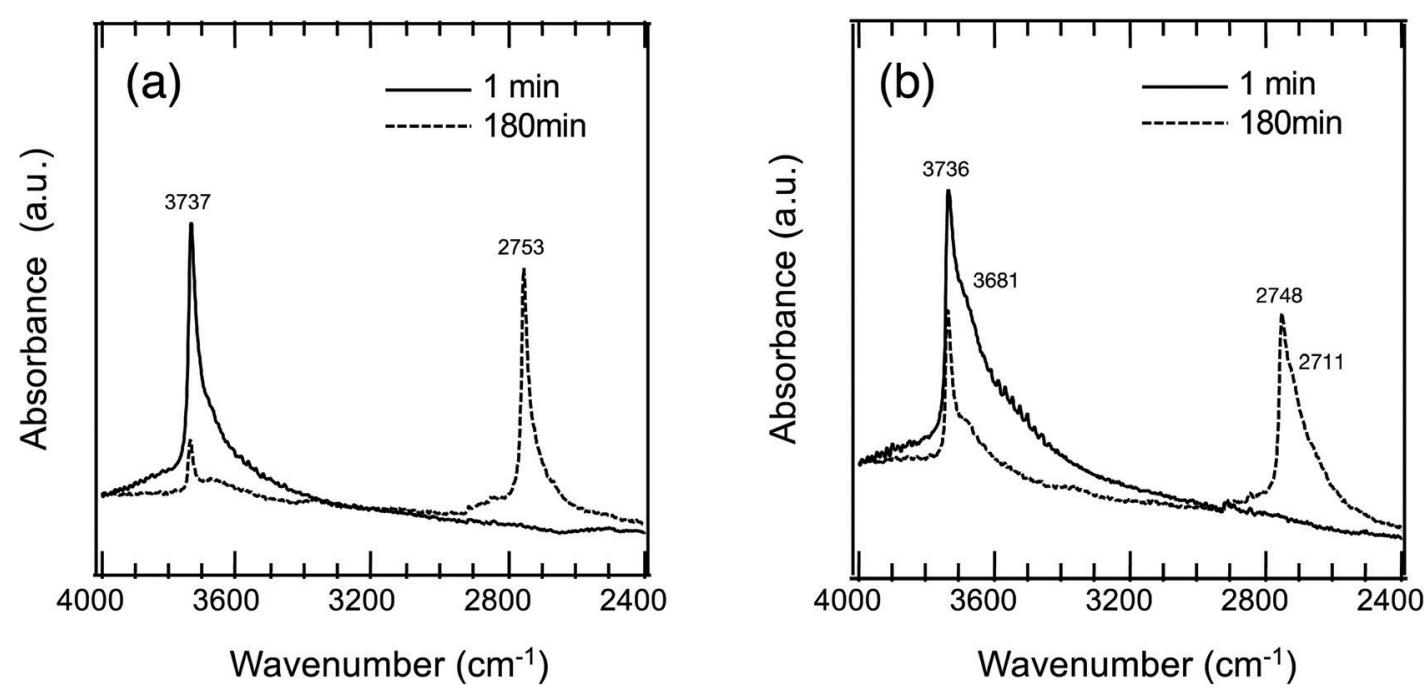

Fig. $5 \mathrm{Si-OH/OD} \mathrm{conversion} \mathrm{behavior} \mathrm{of} \mathrm{(a)} \mathrm{non-doped} \mathrm{and} \mathrm{(b)} \mathrm{Co-doped} \mathrm{amorphous} \mathrm{silica} \mathrm{with} \mathrm{analytical} \mathrm{Co/Si}=0.05$ (CoSiOl $/ 20$ sample) in situ monitored by measuring DRIFT spectra under $10 \% \mathrm{D}_{2} / \mathrm{Ar}$ flow at $500{ }^{\circ} \mathrm{C}$.

Table $3 \mathrm{OH} / \mathrm{OD}$ isotopic shift factor and wavenumber conversion for non-doped and Co-doped amorphous silica synthesized in this study

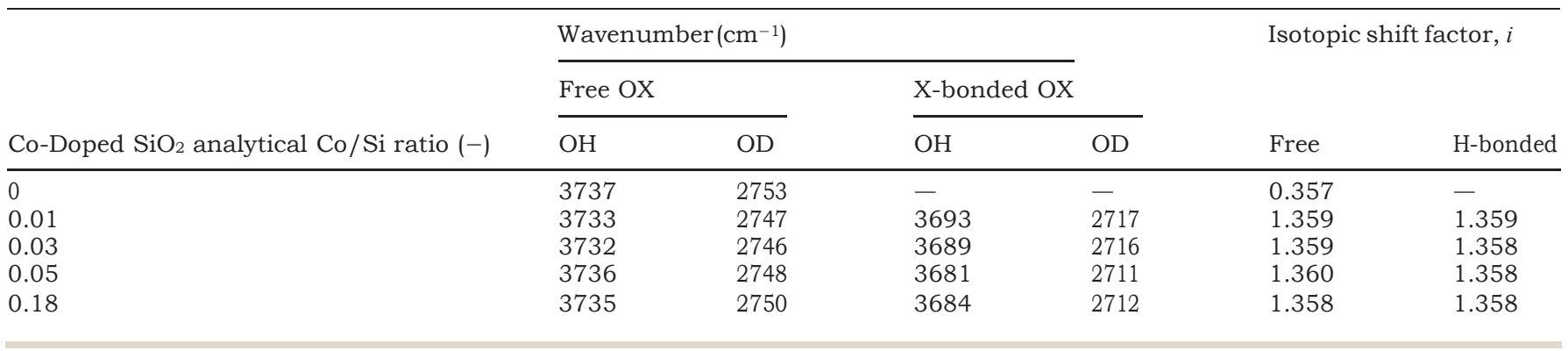

the surface diffusion coefficient and volume diffusion coeffi- cient were in the order of $\sim 10^{-17} \mathrm{~m}^{2} \mathrm{~s}^{-1}$ and $\sim 10^{-24}$ $\mathrm{m}^{2} \mathrm{~s}^{-1}$, respectively.32 In this modelling expressed in eqn (2), the sum-

mation was performed for running indices up to $n=5$. This model can be applied for a very fast exchange on the surface of an oxide particle, whereby $\Delta$ is around $0.5 \mathrm{~nm}$ for typical oxides. ${ }^{33}$ In the present study, the self-diffusion coefficient $(D)$ was adopted as an index of the $\mathrm{Si}-\mathrm{OH} / \mathrm{OD}$ conversion rate on the nondoped and Co-doped amorphous silica surface. The $D$ values were evaluated for the free $\mathrm{Si}-\mathrm{OH}$ and the $\mathrm{H}$-bonded $\mathrm{Si}-\mathrm{OH}$ and were denoted as $D$ (Free) and $D$ (H-bonded), respectively. The $D$ values were estimated by detecting OD generated by exchange on the surface $\mathrm{Si}-\mathrm{OH}$ group by DRIFTS analysis, and $c_{0}$ in this study was renamed as $c_{D}$ eq (the equilibrium deuterium concentration of the sample). Moreover, in this isotope exchange reaction, the monolayer $(\Delta)$ had a nanometer scale thickness, while the radius of the sample particle synthesized in this study had approximately $10 \mu \mathrm{m}$ (one half of $D_{50}$ in Table 2), thus eqn (3) with assuming $r \gg 3 \Delta$ in eqn (2) was employed:
Time dependence on the absorption band intensities of free Si-OD and D-bonded Si-OD in DRIFT spectra was fitted to the non-linear curve using eqn (3) using $r$ as one half of $D_{50}$ listed in Table 2 with two free parameters, $D$ and $c_{D}$ eq.

As a typical result, Fig. 6 presents the $\mathrm{D}_{2}$ gas exposure time dependence of the absorption band intensity evaluated for the free $\mathrm{Si}-\mathrm{OD}$ and the D-bonded $\mathrm{Si}-\mathrm{OD}$ in the CoSiO1/20 sample.

Each fitted line described the experimental data very well, suggesting that $\mathrm{OH} / \mathrm{OD}$ conversions for both the free and $\mathrm{H}$-bonded $\mathrm{Si}-\mathrm{OH}$ investigated in this study were diffusion controlled. In the same manner, the $D$ and $c D$ eq were evaluated for both free and $\mathrm{H}$-bonded $\mathrm{Si}-\mathrm{OH}$ in the Co-doped amorphous silica samples (Fig. SI2 $\dagger$ ), and the results are listed in Table 4. As shown in Fig. 7 , the $D(\mathrm{H}$-bonded) exponentially increased with the $\mathrm{Co} / \mathrm{Si}$ atomic ratio and reached the maximum at $\mathrm{Co} / \mathrm{Si}=0.05$, then decreased with increasing $\mathrm{Co} /$ $\mathrm{Si}$ atomic ratio. The $D$ (Free) also exhibited a similar dependency on the $\mathrm{Co} / \mathrm{Si}$ atomic ratio, however, at all the $\mathrm{Co} / \mathrm{Si}$ atomic ratios, the $D$ (H-bonded) was higher than $D$ (Free). This suggested that the polar $\mathrm{H}$-bonded $\mathrm{Si}-\mathrm{OH}$ formed with the

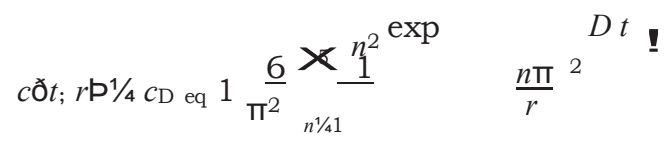

doped $\mathrm{Co}^{2+}$ accelerated the $\mathrm{OH} / \mathrm{OD}$ conversion rate. more details, TEM observations were performed on the 


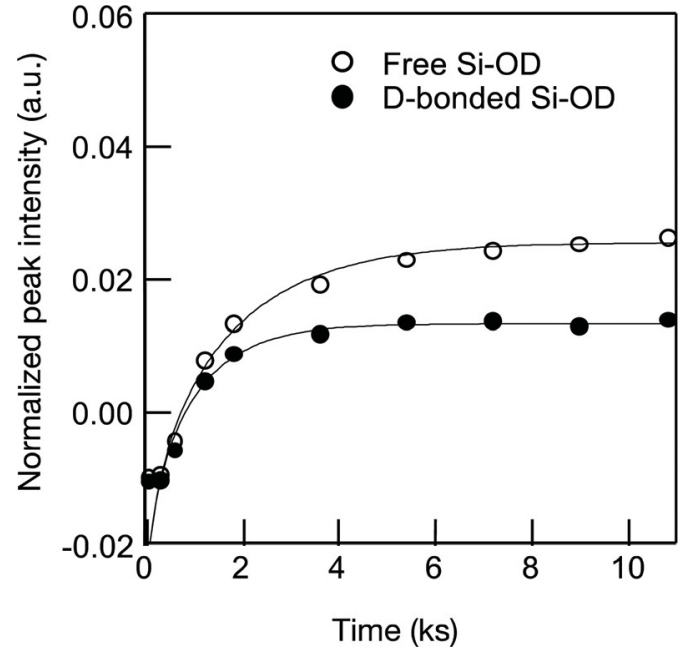

Fig. $6 \mathrm{Si}-\mathrm{OH} / \mathrm{OD}$ conversion of Co-doped amorphous silica with analytical $\mathrm{Co} / \mathrm{Si}=0.05(\mathrm{CoSiO} 1 / 20$ sample $)$.

samples with measured $\mathrm{Co} / \mathrm{Si}=0.05$ (CoSiO1/20 sample) and 0.18 (CoSiO1/8 sample), and the results were shown in Fig. 8 and 9, respectively. $\mathrm{CoSiO} 1 / 20$ and $\mathrm{CoSiO} 1 / 8$ samples were X-ray amorphous (Fig. 3(a)), and the selected area electron diffraction patterns shown in Fig. 8(a) and 9(a) supported the amorphous state of these materials. However, CoSiO1/20 samples sample exhibited some spots with darker contrastless than approximately $2 \mathrm{~nm}$ in size (Fig. 8(b)), and the size of the spots observed for the CoSiO1/8 sample was larger (Fig. 9(b)). As shown in Fig. S3(a), $\dagger$ the CoSiO1/20 sample exhibited a narrow and unimodal spot size distribution, and the mean size was determined as $1.8 \mathrm{~nm}$. On the other hand, the CoSiO1/8 sample showed a wider size distribution with a larger mean size of $3.4 \mathrm{~nm}$ (Fig. S3(b)†). Then, STEM observation was performed for further analysis of the spots. The darker spots observed in the bright field (BF)-images (Fig. 8(c) and 9 (c)) were highlighted with bright contrast in the annular dark-field (ADF)-STEM images (Fig. 8(d) and 9(d)), and the simultaneous electron energy loss spectroscopy (EELS) analysis for the spots shown in Fig. 9(d) resulted in the detection of $\mathrm{Co}^{2+}$ as indicated by the Co LiII/Lil EELS ratio of $\sim 2$ (Fig. 9(e)).

Table 4 Deuterium diffusion coefficient at the surface $(D)$ and $C_{D}$ eq for polymer-derived amorphous silica and Co-doped amorphous silica synthesized in this study

\begin{tabular}{|c|c|c|c|c|}
\hline \multirow[b]{2}{*}{$\begin{array}{l}\text { Co-Doped } \mathrm{SiO}_{2} \text { analytical Co/ } \\
\text { Si ratio (-) }\end{array}$} & \multicolumn{2}{|c|}{$\underline{D\left(10^{-15} \mathrm{~m}^{2} \mathrm{~s}^{-1}\right)}$} & \multicolumn{2}{|c|}{$C_{\underline{D} \_{ }_{\underline{q}}^{e}}\left(10^{-2}\right.$ at $\left.\%\right)$} \\
\hline & $\begin{array}{l}\text { Free } \\
\text { OX }\end{array}$ & $\begin{array}{l}\text { H- } \\
\text { bonded }\end{array}$ & Free & $\begin{array}{l}\text { H- } \\
\text { bonded }\end{array}$ \\
\hline 0 & 6.1 & - & 9.5 & - \\
\hline 0.01 & 3.2 & 4.8 & 4.9 & 3.5 \\
\hline 0.03 & 5.3 & 7.9 & 4.0 & 3.7 \\
\hline 0.05 & 7.6 & 15.6 & 5.8 & 6.3 \\
\hline 0.18 & 5.5 & 9.1 & 5.1 & 4.1 \\
\hline
\end{tabular}

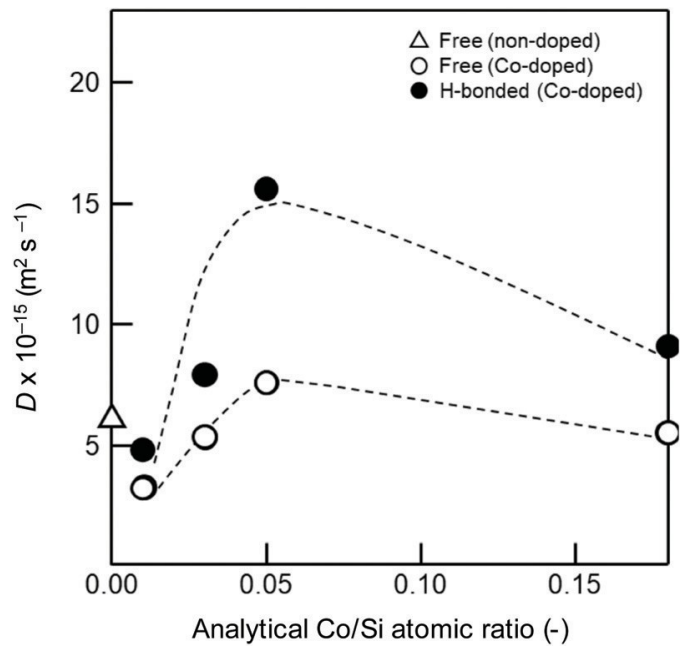

Fig. $7 \mathrm{Co} / \mathrm{Si}$ atomic ratio dependence of the deuterium surface diffusion coefficient, $D$.
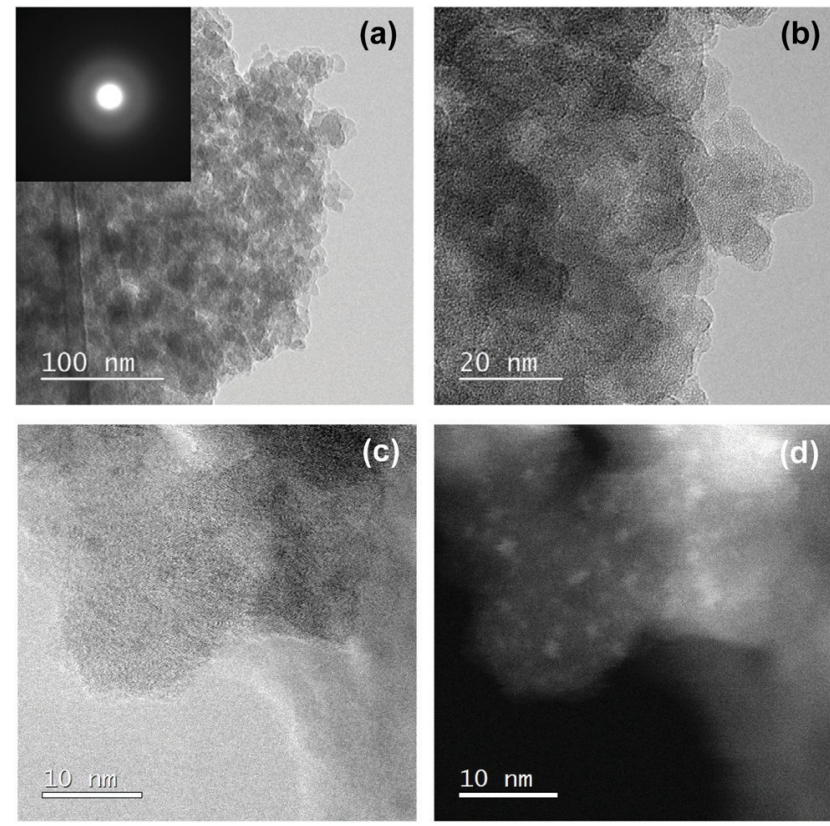

Fig. 8 Nanostructure observation of Co-doped amorphous silica with measured $\mathrm{Co} / \mathrm{Si}=0.05$ (CoSiO1 $/ 20$ sample). (a) TEM image and SAED pattern obtained from the image, (b) high-magnification TEM image (c) BF-STEM image and (d) ADF-STEMimage.

This oxidation state of Co was well consistent with the result obtained by the XPS analysis (Fig. 3(b)).

To study the Co(II)-cluster formation in more detail, HRTEM observation was performed on the samples with a lower Co/Si ratio below 0.05. However, these samples exhibited featureless nanostructures. Then, intensive STEM observation was performed. As a result, the $\mathrm{CoSiO} 1 / 80$ sample exhibited a trace amounts of bright spots with a size of about 1-2 nm under the ADF-STEM imaging mode (Fig. SI4 $\dagger$ ). In the case of the CoSiO1/40 sample, it was also rare to find some spots 

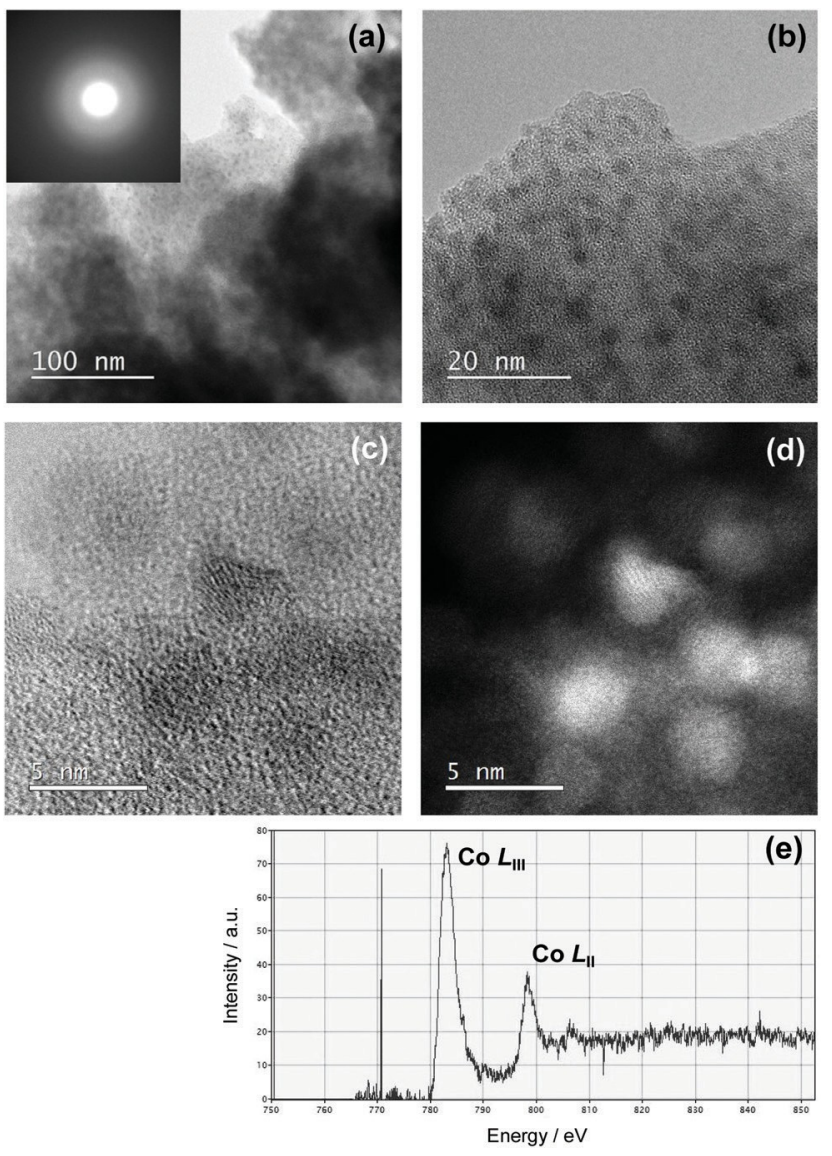

Fig. 9 Nanostructure observation of Co-doped amorphous silica with measured $\mathrm{Co} / \mathrm{Si}=0.18$ (CoSiOl $/ 8$ sample). (a) TEM image and SAED pattern obtained from the image, (b) high-magnification TEM image (c) BFSTEM image, (d) ADF-STEM image and (e) EELS characterization for the spot with bright contrast in (d).

suggested as Co(II)-cluster approximately $2 \mathrm{~nm}$ in size (Fig. SI5†).

As shown in Fig. 7, H-bonded $\mathrm{Si}-\mathrm{OH}$ groups played a key role in the acceleration of the OH/OD conversion rate. Since the parameter of $c$ D eq reflected the number of $\mathrm{Si}-\mathrm{OH}$ which was converted to the $\mathrm{Si}-\mathrm{OD}$ at the sample surface, $D$ values were plotted as a function of $c_{\mathrm{D} \text { eq }}$ (Fig. 10). Consistent with the $c \mathrm{D}$ eq, the $D(\mathrm{H}$-bonded) apparently increased, which indicated that the increase of the number of $\mathrm{H}$-bonded $\mathrm{Si}-\mathrm{OH}$ accelerated the $\mathrm{OH} / \mathrm{OD}$ conversion rate of $\mathrm{Co}^{2+}$-doped amorphous silica. Moreover, as shown in Fig. SI6, $†$ the wavenumber of the $\mathrm{H}$-bonded $\mathrm{OH}\left(\mathrm{v}(\mathrm{OH}) / \mathrm{cm}^{-1}\right)$ in the Co-doped silica samples detected by the IR spectroscopy analysis (Table 3) decreased consistently with $c_{\mathrm{D}}$ eq, i.e. the acidity (polarity) of the $\mathrm{H}$-bonded $\mathrm{OH}$ increased with $c \mathrm{D}$ eq.

As mentioned above, in the case using the conventional sol-gel technique for the synthesis of Co-doped $\mathrm{SiO}_{2}, \mathrm{Co}_{3} \mathrm{O}_{4}$ crystallization easily proceeds to afford the binary $\mathrm{Co}_{3} \mathrm{O}_{4}-\mathrm{SiO}_{2}$ composite. ${ }^{14,15}$ In the present study, amorphous Co(II)-nanocluster formation proceeded to some extent, however, at the $\mathrm{Co} / \mathrm{Si}$ ratios ranging from 0.01 to 0.05 , the concentration of

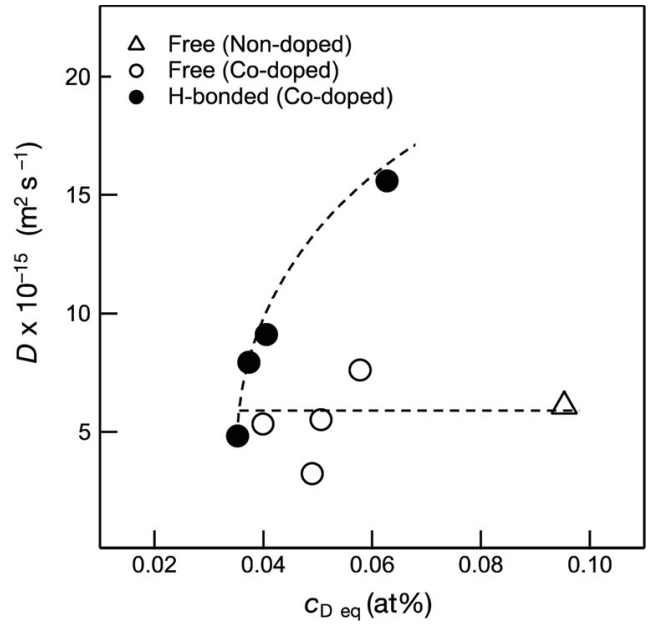

Fig. $10 \mathrm{CD}$ eq dependence of the deuterium surface diffusion coeffi- cient, $D$.

$\mathrm{Co}^{2+}$ which modified the amorphous silica matrix network increased, i.e. number of hydrogen bonds by the doped-Co ${ }^{2+}$ $\left(\mathrm{Si}-\mathrm{O}^{\bar{\delta}} \mathrm{H}^{\bar{\delta}+\ldots} \mathrm{O}-\mathrm{Co}^{2+}\right)$ shown in Fig. 4 increased consistently with the $\mathrm{Co} / \mathrm{Si}$ ratio. This relation was successfully achieved through the present PDCs route: during the thermal conversion of polymer to inorganic compound, the molecular structure having the $\mathrm{Si}-\mathrm{O}-\mathrm{Co}$ bond was preserved to afford the $\mathrm{Co}^{2+}$-induced $\mathrm{H}$-bonded $\mathrm{OH}$ group within the amorphous silica matrix.

Recently, Nogami et al. reported the hydrogen diffusion coefficient through sodium aluminosilicate glasses $\left(\mathrm{Na}_{2} \mathrm{O}-\right.$ $\mathrm{Al}_{2} \mathrm{O}_{3}-\mathrm{SiO}_{2}$ ) prepared by the melt-quenching technique. ${ }^{34}$ The diffusion coefficients of hydrogen at $400-600{ }^{\circ} \mathrm{C}$ estimated for this glass with an $\mathrm{Al} / \mathrm{Na}$ atomic ratio $<1$ were $10^{-16-10^{-15} \mathrm{~m}^{2}}$ $\mathrm{s}^{-1}$ order; as a typical example, the diffusion coefficient at $500{ }^{\circ} \mathrm{C}$ estimated for $20 \mathrm{Na}_{2} \mathrm{O} \cdot 10 \mathrm{Al}_{2} \mathrm{O}_{3} \cdot 70 \mathrm{SiO}_{2}$ glass was $1.8 \times$ $10^{-15} \mathrm{~m}^{2} \mathrm{~s}^{-1} .29$ In this study, as listed in Table 4 , the $D$ (Free) at $500{ }^{\circ} \mathrm{C}$ estimated for non-doped amorphous silica was $6.1 \times$ $10^{-15} \mathrm{~m}^{2} \mathrm{~s}^{-1}$. This value was compatible with the reported value, while the $D\left(\mathrm{H}\right.$-bonded) value of $15.6 \times 10^{-15} \mathrm{~m}^{2} \mathrm{~s}^{-1}$ was approximately one order of magnitude higher than the reported value. Generally, silica-based materials for gas separation membranes are composed of a microporous looser amorphous network which can exhibit molecular sieve property. Thus, hydrogen can permeate through the micropore channels within the amorphous silica, which is recognized as activated diffusion. ${ }^{3}$ The enhanced value of the $D$ (H-bonded) estimated in this study suggests that $\mathrm{Co}^{2+}$-doping can offer an additional hydrogen facilitate transport property at the surface of the micropore channel wall composed of the Co-doped amorphous silica, i.e. enhancing hydrogen permeance via the surface diffusion mechanism even at the high temperature of $500{ }^{\circ} \mathrm{C}$. Alternatively, applications up to $300^{\circ} \mathrm{C}$ will be also attractive; for instance, the hydrogen separation/ purification process for the dehydrogenation of chemical hydrides 35,36 under reduction conditions in novel hydrogen storage-transportation 
systems. Further study on the evaluation of membrane performance as well as lifetime of Co-doped amorphous silica is under progress.

\section{Conclusions}

In this study, the effect of the local structure of polymerderived Co-doped amorphous silica on the hydrogen transport property was intensively studied and the results can be summarized as follows:

(1) $\mathrm{Co}^{2+}$-doped amorphous silica materials with $\mathrm{Co} / \mathrm{Si}$ atomic ratios ranging from 0.01 to 0.18 were successfully synthesized through the PDC route.

(2) The doped $\mathrm{Co}^{2+}$ modified the amorphous silica network to afford $\mathrm{H}$-bonded $\mathrm{Si}-\mathrm{OH}$. The number of the $\mathrm{H}$-bonded $\mathrm{Si}-$ $\mathrm{OH}$ increased consistently with the amount of the doped $\mathrm{Co}^{2+}$ and reached the maximum at the $\mathrm{Co} / \mathrm{Si}$ atomic ratio of 0.05 , then decreased with increasing the $\mathrm{Co} / \mathrm{Si}$ atomic ratio above 0.05 .

(3) HRTEM and STEM analyses revealed that the segregation of $\mathrm{Co}^{2+}$ started at the $\mathrm{Co} / \mathrm{Si}$ atomic ratio of 0.05 , and the amount of $\mathrm{Co}^{2+}$ which modified the amorphous silica network deceased with increasing the $\mathrm{Co} / \mathrm{Si}$ atomic ratio above 0.05 .

(4) The OH/OD conversion behavior for surface silanol groups was in situ monitored by measuring the DRIFT spectra, and the self-diffusion coefficient of deuterium at the sample surface $(D)$ was evaluated. The $D\left(\mathrm{H}\right.$-bonded) at $500{ }^{\circ} \mathrm{C}$ estimated in this study was $15.6 \times 10^{-15} \mathrm{~m}^{2} \mathrm{~s}^{-1}$. This value was approximately one order of magnitude higher than the reported $D$ value at $500{ }^{\circ} \mathrm{C}$ estimated for sodium aluminosilicate glass.

(5) It was found that the enhanced polarity of the H-bonded $\mathrm{Si}-\mathrm{OH}$ formed by the $\mathrm{Co}^{2+}$-doping accelerated the hydrogen transport at the amorphous silica surface network.

(6) The results obtained in this study suggest that a rather small amount of $\mathrm{Co}^{2+}$-doping, expressed as a Co/Si atomic ratio of 0.05 is effective for enhancing hydrogen permeance through microporous amorphous silica membranes at $T \geq$ $500{ }^{\circ} \mathrm{C}$.

\section{Acknowledgements}

This work was partially supported by JSPS KAKENHI Grant Number JP20K05076. Dr Samuel Bernard and Prof. Yuji Iwamoto would like to thank CNRS who financially supported the present work via the International Research Project (IRP) 'Ceramics materials for societal challenges'.

\section{References}

1 R. M. De Vos and H. Verweij, High-selectivity, high-flux silica membranes for gas separation, Science, 1998, 279, 1710-1711.

2 Y. Iwamoto, K. Sato, T. Kato, T. Inada and Y. Kubo, A hydrogen-permselective amorphous silica membrane derived from polysilazane, J. Eur. Ceram. Soc., 2005, 25, 257-264.

3 Y. Iwamoto, Precursors-Derived Ceramic Membranes for High-Temperature Separation of Hydrogen, J. Ceram. Soc. Jpn., 2007, 115, 947-954.

4 T. Nagano, S. Fujisaki, K. Sato, K. Hataya, Y.Iwamoto, M. Nomura and S.-I. Nakao, Relationship between the Mesoporous Intermediate Layer Structure and the Gas Permeation Property of an Amorphous Silica Membrane Synthesized by Counter Diffusion Chemical Vapor Deposition, J. Am. Ceram. Soc., 2008, 91(1), 71-76.

5 A. K. Prabhu and S. T. Oyama, Highly hydrogen selective ceramic membranes: Application to the transformation of greenhouse gases, J. Membr. Sci., 2000, 176, 233-248.

6 S. Kurungot, T. Yamaguchi and S. I. Nakao, $\mathrm{Rh} / \mathrm{Y}-\mathrm{Al}_{2} \mathrm{O}_{3}$ catalytic layer integrated with sol-gel synthesized microporous silica membrane for compact membrane reactor applications, Catal. Lett., 2003, 86, 273-278.

7 K. Akamatsu, T. Murakami, T. Sugawara, R. Kikuchi and S. Nakao, Stable equilibrium shift of methane steam reforming in membrane reactors with hydrogen-selective silica membranes, AIChE J., 2011, 57, 1882-1888.

8 K. Akamatsu, Y. Ohta, T. Sugawara, N. Kanno, K. Tonokura, T. Hattori and S. Nakao, Stable high-purity hydrogen production by dehydrogenation of cyclohexane using a membrane reactor with neither carrier gas nor sweep gas, J. Membr. Sci., 2009, 330, 1-4.

9 K. Akamatsu, Y. Ohta, T. Sugawara, T. Hattori and S. Nakao, Production of hydrogen by dehydrogenation of cyclohexane in high-pressure (1-8 atm) membrane reactors using amorphous silica membranes with controlled pore sizes, Ind. Eng. Chem. Res., 2008, 47, 9842-9847.

10 K. Akamatsu, T. Tago, M. Seshimo and S. Nakao, Longterm stable $\mathrm{H}_{2}$ production from methylcyclohexane using a membrane reactor with a dimethoxydiphenylsilane-derived silica membrane prepared via chemical vapor deposition, Ind. Eng. Chem. Res., 2015, 54, 3996-4000.

11 X. L. Zhang, K. Akamatsu and S. Nakao, Hydrogen Separation in Hydrogen-Methylcyclohexane-Toluene Gaseous Mixtures through Triphenylmethoxysilane-Derived Silica Membranes Prepared by Chemical Vapor Deposition, Ind. Eng. Chem. Res., 2016, 55, 5395-5402.

12 K. Yoshida, Y. Hirano, H. Fujii, T. Tsuru and M. Asaeda, Hydrothermal Stability and Performance of Silica-Zirconia Membranes for Hydrogen Separation in Hydrothermal Conditions, J. Chem. Eng. Jpn., 2001, 34, 523-530.

13 M. Kanezashi and M. Asaeda, Hydrogen permeation characteristics and stability of Ni-doped silica membranes in steam at high temperature, J. Membr. Sci., 2006, 271, 8693. 
14 R. Igi, T. Yoshioka, Y. H. Ikuhara, Y. Iwamoto and T. Tsuru, Characterization of co-doped silica for improved hydrothermal stability and application to hydrogen separation membranes at high temperatures, J. Am. Ceram. Soc., 2008, 91, 2975-2981.

15 S. Fujisaki, K. Hataya, T. Saito, S. Arai, Y. Iwamoto and K. Kuroda, Nanostructural characterizations of hydrogenpermselective Si-Co-O membranes by transmission electron microscopy, J. Mater. Res., 2009, 24, 372-378.

16 C. R. Miller, D. K. Wang, S. Smart and J. C. Diniz da Costa, Reversible redox effect on gas permeation of cobalt doped ethoxy polysiloxane (ES40) membranes, Sci. Rep., 2013, 3, $1-6$.

17 T. Kubo and H. Kozuka, Conversion of Perhydropolysilazane-to-Silica Thin Films by Exposure to Vapor from Aqueous Ammonia at Room Temperature, J. Ceram. Soc. Jpn., 2006, 114, 517-523.

18 M. N. Mohd Sokri, T. Onishi, Y. Daiko, S. Honda and Y. Iwamoto, Hydrophobicity of amorphous silica-based inorganic-organic hybrid materials derived from perhydropolysilazane chemically modified with alcohols, Microporous Mesoporous Mater., 2015, 215, 183-190.

19 M. Mohd Sokri, Y. Daiko, Z. Mouline, S. Honda and Y. Iwamoto, Formation of Micro and Mesoporous Amorphous Silica-Based Materials from Single Source Precursors, Inorganics, 2016, 4, 5.

20 C. Zhou, C. Fasel, R. Ishikawa, M. Gallei, Y. Ikuhara, S. Lauterbach, H. J. Kleebe, R. Riedel and E. Ionescu, Onepot synthesis of a $\mathrm{C} / \mathrm{SiFeN}(\mathrm{O})$-based ceramic paper with in situ generated hierarchical micro/nano-morphology, $J$. Eur. Ceram. Soc., 2017, 37, 5193-5203.

21 P. J. Launer, Infrared Analysis of Organosilicon Compounds: Spectra-structureCorrelations, Laboratory for Materials, Inc. Burnt Hills, New York, 1987.

22 J. E. Stewart, Vibrational spectra of primary and secondary aliphatic amines, J. Chem. Phys., 1959, 30, 1259-1265.

23 Y.Iwamoto, K. Kikuta and S. Hirano, Microstructuraldevelopment of $\mathrm{Si}_{3} \mathrm{~N}_{4}-\mathrm{SiC}-\mathrm{Y}_{2} \mathrm{O}_{3}$ ceramics derived from polymeric precursors, J. Mater. Res., 1998, 13, 353-361.

24 M. A. Langell, M. D. Anderson, G. A. Carson, L. Peng and S. Smith, Valence-band electronic structure of $\mathrm{Co}_{3} \mathrm{O}_{4}$ epitaxy on CoO(100), Phys. Rev. B: Condens. Matter Mater. Phys., 1999, 59, 4791-4798.

25 B. A. F. Kengne, A. M. Alayat, G. Luo, A. G. McDonald, J. Brown, H. Smotherman and D. N. McIlroy, Preparation, surface characterization and performance of a FischerTropsch catalyst of cobalt supported on silica nanosprings, Appl. Surf. Sci., 2015, 359, 508-514.
26 R. M. Silverstein, G. C. Bassler and T. C. Morrill, Spectrometric Identification of Organic Compounds, J. Wiley \& Sons, New York, 1991.

27 Z. Mouline, K. Asai, Y. Daiko, S. Honda, S. Bernard and Y. Iwamoto, Amine-functionalized polycarbosilane hybrids for $\mathrm{CO}_{2}$-selective membranes, J. Eur. Ceram. Soc., 2017,37, 5213-5221.

28 C. Pazé, S. Bordiga, C. Lamberti, M. Salvalaggio, A. Zecchina and G. Bellussi, Acidic Properties of H- $\beta$, Zeolite As Probed by Bases with Proton Affinity in the 118-204 kcal mol-1 Range: A FTIR Investigation, J. Phys. Chem. B, 1997, 101, 4740-4751.

29 E. Groppo, C. Lamberti, S. Bordiga, G. Spoto and A. Zecchina, The Structure of Active Centers and the Ethylene Polymerization Mechanism on the $\mathrm{Cr} / \mathrm{SiO}_{2}$ Catalyst: A Frontier for the Characterization Methods, Chem. Rev., 2005, 105, 115-183.

30 K. Chakarova, N. Drenchev, M. Mihaylov, P. Nikolov and K. Hadjiivanov, OH/OD isotopic shift factors of isolated and H-bonded surface silanol groups, J. Phys. Chem. C, 2013, 117, 5242-5248.

31 A. B. Gizhevskii, A. Y. Fishman, E. A. Kozlov, T. E. Kurennykh, S.A. Petrova, I. S. Trakhtenberg, E. V. Vykhodets, V. B. Vykhodets and R. G. Zakharov, Oxygen Isotope Exchange between Gaseous Phase Enriched with 8 Is Isotope and Nanocrystal Oxides $\mathrm{LaMnO}_{3+\bar{\delta}}$, obtained by severe plastic deformation, Defect Diff $u$ s. Forum, 2008, 233, 273-276.

32 A. Y. Fishman, T. E. Kurennykh, S. A. Petrova, E. V. Vykhodets, V. B. Vykhodets and R. G. Zakharov, Oxygen isotope exchange in nanocrystal oxide powders, J. Nano Res., 2009, 7, 33-41.

33 E. R. Trejo and J. A. Kilner, Oxygen diffusion and proton conduction in $\mathrm{La}_{1-\mathrm{x}} \mathrm{Sr}_{\mathrm{x}} \mathrm{YO}_{3-\mathrm{d}}$, Solid State Ionics, 1997, 97, 529-534.

34 M. Nogami, V. X. Quang, S. Ohki, K. Deguchi and T. Shimizu, Reduction Mechanisms of $\mathrm{Cu}^{2+}$-Doped $\mathrm{Na}_{2} \mathrm{O}-\mathrm{Al}_{2} \mathrm{O}_{3}-\mathrm{SiO}_{2}$ Glasses during Heating in $\mathrm{H} 2$ Gas, J. Phys. Chem. B, 2018, 122,1315-1322.

35 K. Oda, K. Akamatsu, T. Sugawara, R. Kikuchi, A. Segawa and S. Nakao, Dehydrogenation of Methylcyclohexane To Produce High-Purity Hydrogen Using Membrane Reactors with Amorphous Silica Membranes, Ind. Eng. Chem. Res., 2010, 49, 11287-11293.

36 K. Kida, Y. Maeta, T. Kuno and K. Yogo, Hydrogen Purification from Chemical Hydride Using Pure Silica Zeolite Membranes, Chem. Lett., 2017, 46, 1724- 1727. 